\title{
MERANCANG APLIKASI SMS GATEWAY MENGGUNAKAN GAMMU DAN MODEM ZTE 190 PADA SISWA SMA PANTI BUDAYA KISARAN
}

\author{
${ }^{1)}$ Rizaldi, ${ }^{2)}$ Febri Dristyan, ${ }^{3)}$ Mardalius \\ ${ }^{1,2,3)}$ Sistem Informasi, Sekolah Tinggi Manajemen Informatika dan Komputer Royal \\ 1,2,3) Jl. H.M Yamin, No. 173 Kisaran, Asahan - Sumatera Utara - Indonesia \\ E-mail: rizaldipiliang.rp@gmail.com,fdristyan@gmail.com,mardalius18@gmail.com
}

\begin{abstract}
ABSTRAK
Kurangnya pengetahuan siswa SMA Panti Budaya Kisaran dalam memahami perkembangan teknologi informasi khususnya sistem informasi berbasis SMS Gateway, menjadi alasan bagi Tim PKM STMIK Royal Kisaran melakukan kegiatan abdimas dengan tema "Merancang Aplikasi SMS Gateway Menggunakan Gammu dan Modem ZTE 190 Pada Siswa SMA Panti Budaya Kisaran". Metode pelaksanaan kegiatan dilakukan dengan 2 cara, yaitu ceramah dan pelatihan. Dalam kegiatan tersebut siswa diberikan penjelasan tentang sistem informasi berbasis SMS Gateway kemudian setelah itu siswa dilatih bagaimana merancang aplikasi SMS Gateway. Tujuan dari kegiatan ini adalah membekali siswa dengan kemampuan (skill) dalam merancang aplikasi SMS Gateway, lalu dengan skill tersebut siswa dapat menerapkannya pada dunia pekerjaan pada masa yang akan datang. Setelah melalui menjelasan dan pelatihan oleh Tim PKM STMIK Royal Kisaran, siswa telah berhasil membangun aplikasi SMS Gateway dengan baik dan benar.
\end{abstract}

Kata Kunci: SMS Gateway, Gammu, Modem ZTE 190, SMA Panti Budaya Kisaran

\begin{abstract}
The lack of knowledge of students of SMA Panti Budaya Kisaran in understanding the development of information technology, especially SMS Gateway based information systems, was the reason for the STMIK Royal Kisaran Team to carry out community service activities with the theme "Designing SMS Gateway Applications Using Gammu and ZTE 190 Modems for students of SMA Panti Budaya Kisaran". The method of implementing the activity is carried out in 2 ways, namely lectures and training. In this activity the students were given an explanation of the SMS Gateway based information system and after that the students were trained how to design the SMS Gateway application. The purpose of this activity is to equip students with skills in designing the SMS Gateway application, then with these skill students can apply them to the world of work in the future. After going through explanation and training by the STMIK Royal Kisaran Team, the students have succeeded in building the SMS Gateway application properly.
\end{abstract}

Keyword: SMS Gateway, Gammu, Modem ZTE 190, SMA Panti Budaya Kisaran

\section{PENDAHULUAN}

Teknologi sistem informasi hadir dalam berbagai model untuk mendukung kinerja perusahaan/organisasi[1][2]. Sesuai dengan kebutuhan organisasi, hampir setiap perusahaan membangun sistem informasi pada divisi-divisi dalam organisasi guna mengefektifkan dan mengefesienkan kinerja personil dalam organisasi tersebut. Misalnya, Sistem Informasi Akuntansi menggunakan aplikasi Myob untuk mendukung kinerja bagian keuangan. Sistem Informasi Pemasaran untuk mendukung kinerja bagian promosi dan penjualan, Sistem Informasi Eksekutif untuk mendukung kinerja bagian Esekutif, dan sistem informasi lainnya. Sistem informasi adalah suatu sistem di dalam suatu organisasi yang mempertemukan kebutuhan pengolahan transaksi harian yang mendukung fungsi operasi organisasi yang bersifat manajerial dengan kegiatan strategi dari suatu organisasi untuk dapat menyediakan kepada pihak luar tertentu dengan laporan-laporan yang diperlukan[3][4]. Selain model, proses pengolahan data dan luaran dari proses data sistem informasi juga memiliki beragam cara mengeksekusi data menjadi informasi. Salah satunya menggunakan aplikasi SMS Gateway. SMS (Short Message Service) Gateway/SMS Gateway adalah komunikasi melalui SMS yang di dalamnya terdapat beberapa informasi, berupa nomor telepon seluler baik pengirim maupun penerima SMS, waktu, dan konten pesan yang disampaikan[5]. 
SMA Panti Budaya Kisaran merupakan salah satu SMA Swasta yang siswa kelas XII tidak hanya berfokus pada mata pelajaran sesuai dengan jurusan yang mereka ambil saja, akan tetapi dianjurkan untuk memahami ilmu pengetahuan lain yang dapat mencerdaskan siswa tersebut. Berkaitan dengan tema kegiatan abdimas oleh Tim PKM STMIK Royal, pada dasarnya siswa SMA Panti Budaya tidak mengetahui apa itu sistem informasi berbasis SMS Gateway secara mendalam, apa tujuan dan manfaat sistem tersebut bagi organisasi dan apa pula manfaat bagi mereka jika mengetahui dan memahami sistem informasi berbasis SMS Gateway.

Berdasarkan kurangnya pengetahuan siswa SMA Panti Budaya dalam memahami perkembangan teknologi informasi khususnya sistem informasi berbasis SMS Gateway, maka hal tersebut yang menjadi alasan bagi Tim PKM STMIK Royal Kisaran melakukan kegiatan abdimas dengan tema "Merancang Aplikasi SMS Gateway Menggunakan Gammu dan Modem ZTE 190 Pada Siswa SMA Panti Budaya Kisaran". Dalam kegiatan tersebut siswa diberikan penjelasan tentang sistem informasi berbasis SMS Gateway dan diberikan pelatihan bagaimana merancang aplikasi SMS Gateway.

\section{METODE PELAKSANAAN}

Tahapan atau langkah-langkah yang ditempuh untuk kelancaran dan tercapainya tujuan kegiatan pengabdian kepada masyarakat ini adalah:

1. Mempersiapkan materi yang akan diberikan, baik modul, slide presentasi, dan alat peraga lainnya.

2. Memastikan tempat dan fasilitas pendukung seperti in focus, projector, dan lain-lain sudah standby pada saat kegiatan akan dilangsungkan.

3. Pemaparan pengetahuan dasar sistem informasi berbasis SMS Gateway dalam mendukung kinerja organisasi.

4. Pemaparan pengetahuan tentang sistem informasi dan peranan sistem informasi dalam berbagai bidang dalam organisasi.

5. Pelatihan merancang sistem informasi berbasis SMS Gateway Menggunakan Gammu dan Modem ZTE 190.

6. Diskusi dan tanya jawab.

Dalam kegiatan ini kepala sekolah menyediakan tempat selama kegiatan dilangsungkan dan fasilitas-fasilitas penunjang yang mereka punya untuk mendukung kegiatan ini berjalan dengan baik dan lancar.

\section{HASIL}

\section{Kebutuhan Software dan Peralatan Pendukung SMS Gateway}

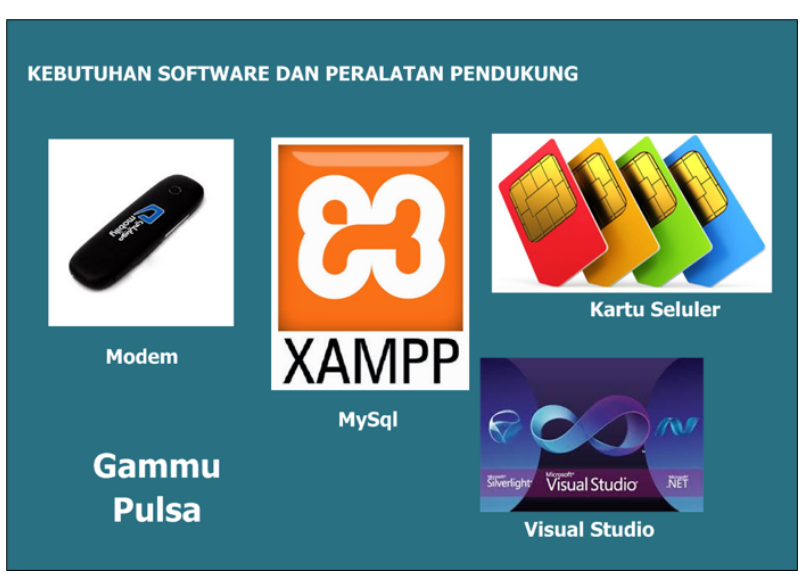

Gambar 8. Software dan Peralatan Pendukung SMS Gateway 


\section{Installasi Software dan Pengaturan Peralatan Pendukung}

1. Install Modem

2. Install Xampp

3. Install Visual Studio $\rightarrow$ VBNet 2010

4. Install Gammu

Setelah semua software di atas diinstall, lakukan pengaturan-pengaturan sebagai berikut:

1. Masuk ke dalam device manager, cari modem, dan pilih ZTE Proprietary USB modem, Cek port pada men modem dan klik OK.

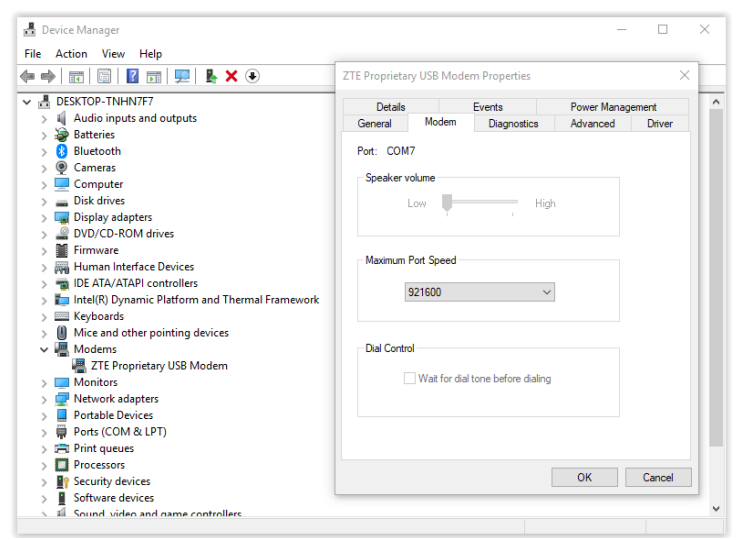

Gambar 9. Device Manager

2. Lakukan pengaturan pada Gammu

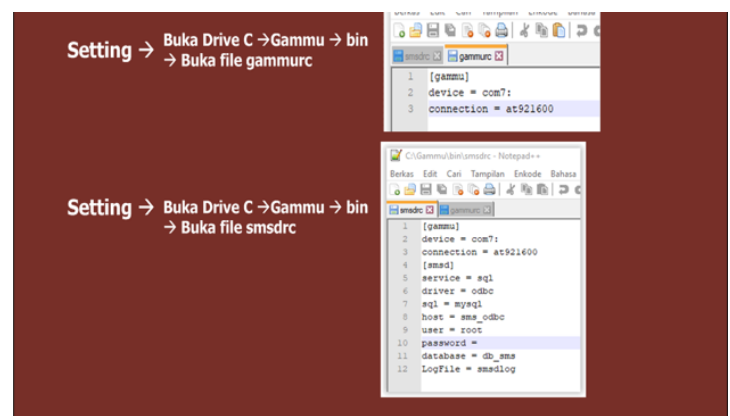

Gambar 10. Pengaturan Gammu

3. Cek keterhubugan Gammu dengan modem.

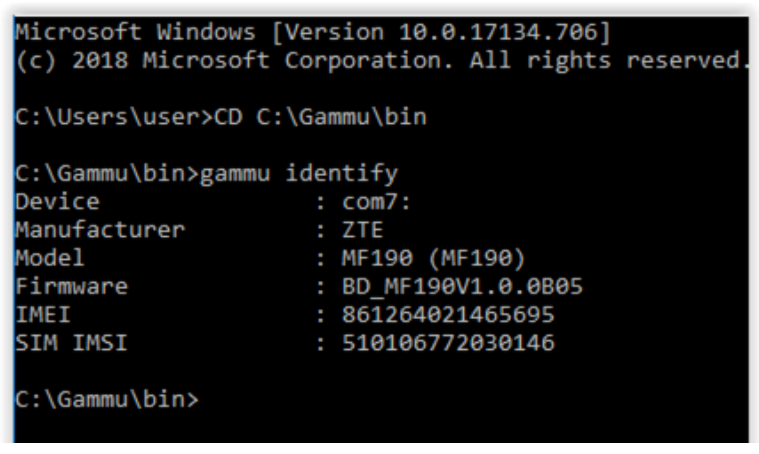

Gambar 11. Koneksi Gammu Melalui Command Prompt 
4. Buat database dan lakukan pengaturan database sebagai berikut:

a. Import tabel bawaan gammu ke dalam database yang sudah dibuat

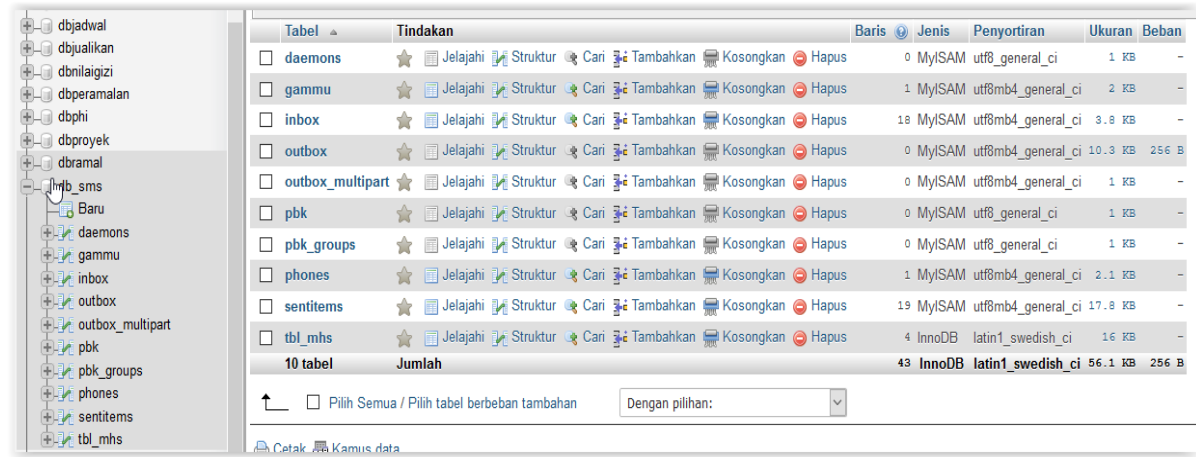

b. Configurasi nama database melalui ODBC untuk menguji apakah database sudah tersambung dengan gammu. Jika belum ada ODBC, silahkan download di alamat ini https://dev.mysql.com/downloads/connector/odbc/. Download dan install 2 file berikut ini:

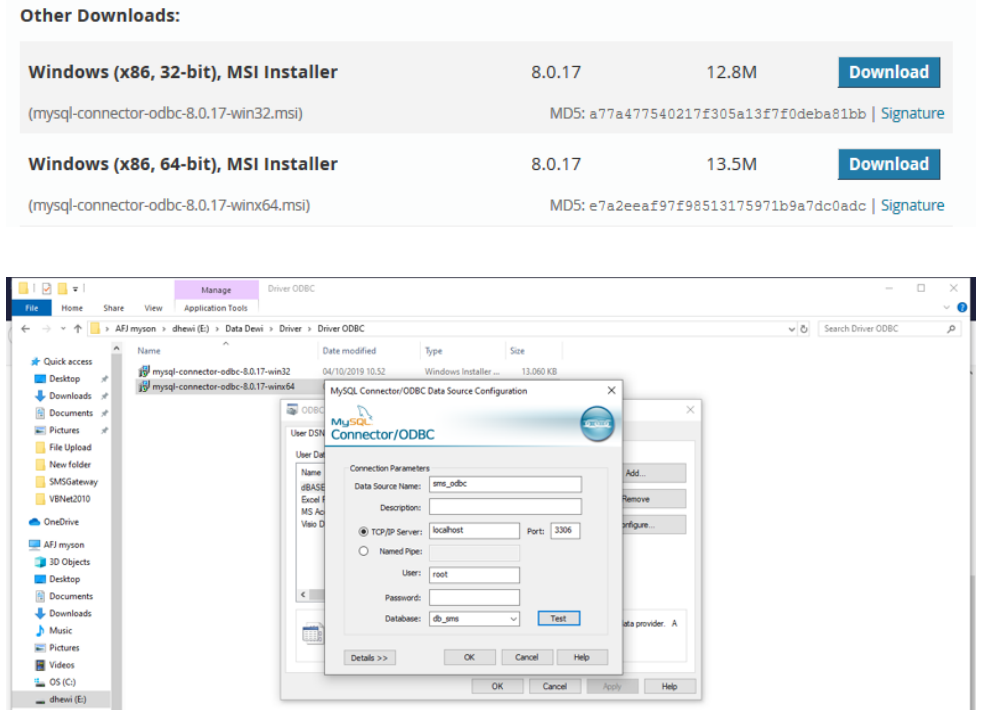

c. Setelah itu tulis "gammu-smsd -c smsdrc" pada command prompt.

\section{Aplikasi SMS Gateway menggunakan VBNet 2010}

Contoh kasus adalah tentang pembayaran uang sekolah. Berikut bentuk form aplikasinya.

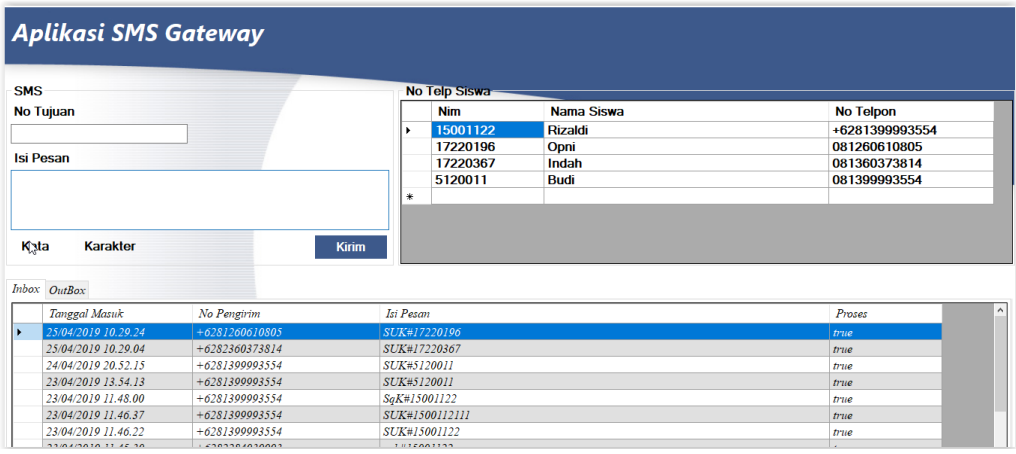

Operator dapat membetahukan orang tua siswa tentang pembayaran uang sekolah melalui form 
aplikasi di atas dengan cara memasukan No. Hp tujuan/orang tua dan memberi pesan pada kotak isi pesan. Kemudian menekan tombol kirim untuk mengirim pesan.

Untuk auto replay, orang tua siswa cukup mengirim pesan ke No. tujuan yang sudah ditentukan oleh sistem dengan mengetik format sebagai berikut (contoh):

SUK\#17220196. SUK kode untuk kode pembayaran uang sekolah sedangkan angka setelah pagar merupakan nomor induk siswa. Kemudian sistem langsung akan membalas kenomor orang tua, misalnya dengan pesan "Sisa Uang Kuliah Nim: 17220196 Nama: Rizaldi Sebesar : Rp.Rp. 50.000,-“. Jika format yang diketik salah, maka sistem akan membalas dengan pesan seperti ini: "Maaf..! Nim Mahasiswa Salah".

\section{Dokumentasi Kegiatan}

Gambar dibawah ini merupakan kegiatan pelaksanaan PKM oleh tim dosen dan mahasiswa STMIK Royal Kisaran dan gambar foto bersama setelah selesai kegiatan. Pada prakteknnya pelatihan hanya diberikan ke beberapa siswa saja disebabkan karena fasilitas kurang mendukung. Akan tetapi penjelasan detail tetap disampaikan dengan sekaligus cara merancang SMS Gateway dari awal sampai dengan selesai.
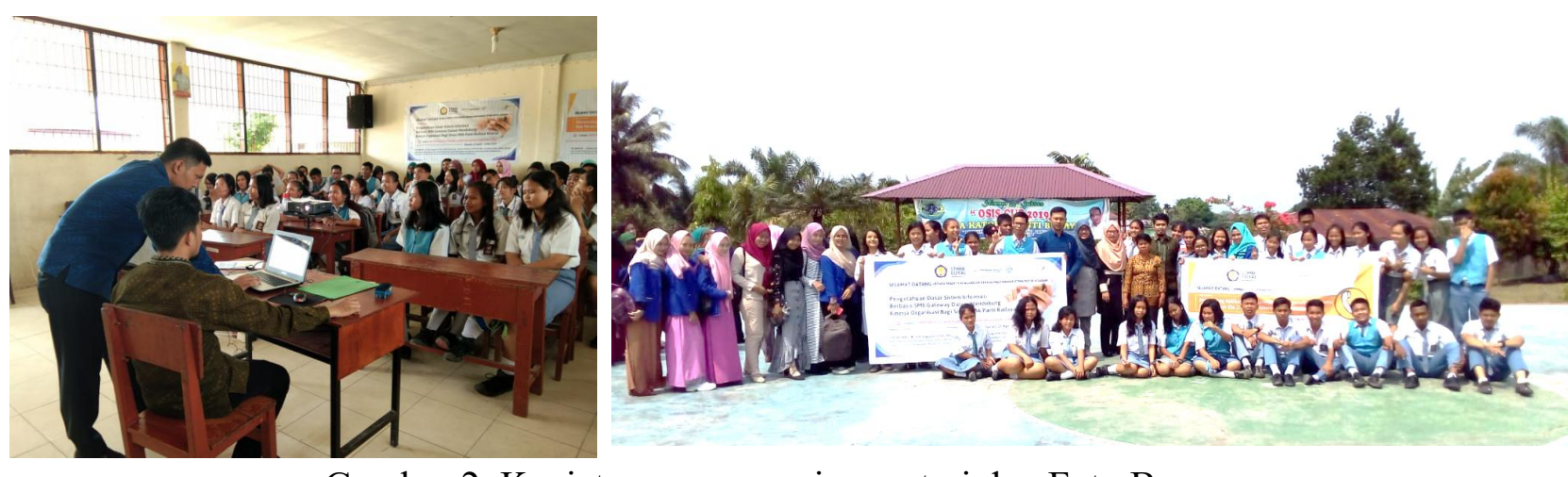

Gambar 2. Kegiatan penyampaian materi dan Foto Bersama

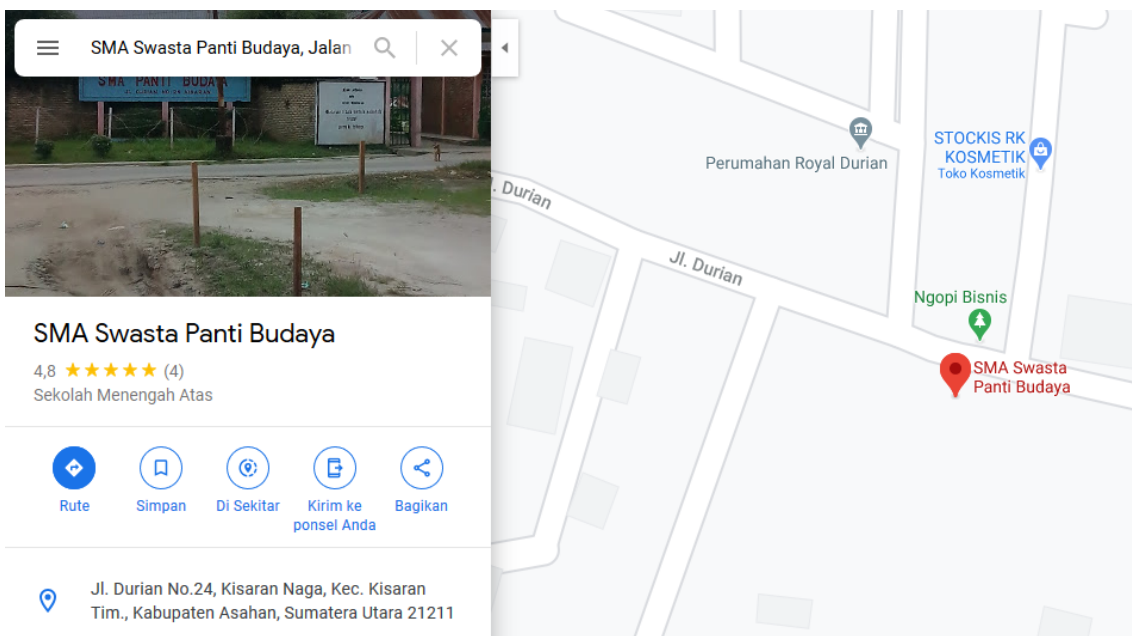

Gambar 4. Lokasi kegiatan 


\section{KESIMPULAN}

Kegiatan pengabdian kepada masyarakat yang dilakukan oleh Tim kegiatan (dosen dan mahasiswa STMIK Royal Kisaran) tepat pada sasaran. Materi kegiatan yang diberikan kepada peserta dapat digunakan dan dimanfaatkan sebagai dasar pengetahuan dalam membangun sistem informasi berbasis SMS Gateway. Materi yang disampaikan kepada peserta mencapai 95\% dari semua konsep yang telah dipersiapkan sebelumnya. Penyampaian materi terdiri dari beberapa sesi, yaitu: pemaparan, praktek, dan diskusi.

\section{DAFTAR PUSTAKA}

[1] R. Rizaldi, "Penentuan Operator Kartu Seluler Terbaik Menggunakan Metode Ahp(Analitycal Hierarchy Process)," J. Teknol. Inf., vol. 1, no. 1, pp. 61-67, 2017, doi: 10.36294/jurti.v1i1.44.

[2] F. D. Romy Aulia, Mardalius Mardalius, "PENINGKATAN PEMANFATAN PERAN TEKNOLOGI INFORMASI BAGI PESERTA DIDIK LKP BINTANG MULIA BATUBARA," vol. 2, no. 1, pp. 49-52, 2019, doi: https://doi.org/10.33330/jurdimas.v2i1.320.

[3] Rizaldi, "Penerapan Waterfall Dalam Membangun Sistem Informasi Pengolahan Data," vol. IV, no. 1, pp. 71-80, 2017, [Online]. Available: https://jurnal.stmikroyal.ac.id/index.php/jurteksi/article/view/26.

[4] D. Anggraeni, "Sistem Informasi Pengelolaan Daerah Aliran Sungai Di BPDAS Kota Padang," Jurteksi, vol. 4, no. 1, pp. 29-36, 2017, doi: 10.33330/jurteksi.v4i1.21.

[5] Rizaldi and A. Z. Syah, "Monitoring Orang Tua Terhadap Pembayaran Uang Kuliah Dan Absensi Mahasiswa Berbasis SMS Gateway," J. Ris. Komput., vol. 6, no. 4, pp. 374-380, 2019, [Online]. Available:

budidarma.ac.id/index.php/jurikom/article/view/1332/0. 